\title{
A RESPONSABILIDADE DOS ESTADOS PELA PRÁTICA DE ATOS ILÍCITOS INTERNACIONAIS
}

\author{
Roberto Chacon de Albuquerque \\ Doutorando em Direito Civil pela Faculdade de Direito da \\ Universidade de São Paulo. Advogado em São Paulo e Brasília.
}

\begin{abstract}
Resumo:
A teoria da responsabilidade do Estado em seus aspectos centrais, envolvendo os casos de tratamento dados aos estrangeiros, além de direitos e deveres garantidos aos cidadãos fora do Estado de origem, em consonância com a legislação nacional de cada país. Outras espécies de responsabilidade do Estado, incluso relação a tratados comerciais, com ênfase aos cidadãos que vivem no Exterior.
\end{abstract}

Abstract:

The State's liability theory on its central aspects, involving the cases of foreigner's treatment, in addition to the rights and duties guaranteed to the citizens out of the origin State, keeping with the national legislation of each country. Another species of liability, added the ones related to the comercial agreement, emphasized the citizens that live in the Exterior.

Unitermos: projeto de responsabilidade do Estado; ato ilícito internacional; crimes contra a Paz; segurança da Humanidade.

Introdução.

Os aspectos centrais da teoria da responsabilidade dos Estados pela prática de atos ilícitos internacionais desenvolveram-se a partir de casos envolvendo o tratamento de estrangeiros e o assim chamado padrão mínimo internacional.' Os direitos e deveres dos estrangeiros são disciplinados pela legislação nacional de cada país e por tratados. Quando o tratamento concedido a um estrangeiro não corresponde ao padrão mínimo exigido pelo Direito Internacional, o Estado em questão é considerado então como tendo violado um interesse resguardado pelo Direito Internacional em benefício do Estado de origem do estrangeiro. ${ }^{2}$ A responsabilidade internacional do Estado diz

I. MALANCZUK, Peter. Akehurst's Modern Introduction to International Law. Londres/Nova York: Routledgc, $7^{\star 2}$ cd., p. 256.

2. BISHOP, WM. W. Gencral Course of Public International Law. In: Recueil des Cours 1965. Lcydc: Acadćmic de Droit Intcrnational, (115):385, 1965. 
respeito, tradicionalmente, portanto, sobretudo aos danos causados a estrangeiros. ${ }^{3}$ Existem outras espécies de responsabilidade do Estado por atos ilícitos internacionais, tais como a proveniente de danos causados diretamente a outro Estado. Quando se discorre sobre a responsabilidade internacional do Estado com relação a tratados comerciais, trata-se de uma parte do Direito Internacional com conseqüências imediatas e práticas também para os cidadãos que não vivem no Exterior. ${ }^{4} \mathrm{~A}$ responsabilidade é o corolário do direito. A violação de todo direito com projeção internacional enseja, ainda que potencialmente, a responsabilidade do Estado que o violou. ${ }^{5}$

Quando um Estado pratica ou facilita a prática de um ato ilícito internacional, ele pode se tornar responsável pela prática deste ato. ${ }^{6}$ Um ato internacionalmente ilícito pode consistir, por exemplo, na violação de direitos públicos ou privados de estrangeiros. Os direitos de seus próprios cidadãos (escravidão, genocídio, apartheid ou outras violações aos direitos humanos), bem como os direitos de um grupo étnico (por exemplo, o direito à autodeterminação), também podem ser objeto de um ato ilícito internacional. ${ }^{7} \mathrm{O}$ ato ilícito pode ir de encontro aos direitos de um Estado, ${ }^{8}$ de um grupo de Estados, ${ }^{9}$ de um sujeito de Direito Internacional que não seja um Estado ${ }^{10}$ ou da comunidade internacional como um todo ${ }^{11}$ e 12 Se um Estado viola uma norma de Direito consuetudinário Internacional, que se consolida em função da práxis desenvolvida pelos Estados, ${ }^{13}$ ou uma obrigação proveniente de um tratado

3. Idem, ibidem, p. 384: "When we speak of 'State Responsibility' we mean that area of international law which from the standpoint of the defendant state is thought of as 'State responsibility for injury to aliens'; from the plaintiff state regarded as 'Diplomatic protection of citizens abroad'; and from the procedural standpoint described as "International claims" "

4. Id., ib., p. 384.

5. GRAY, Christinc. Is There an International Law of Remedics. The British Year Book of International Law 1985. Oxford: Clarendon Press, 1986, p. 29: "Perhaps the best-known judicial statement on this topic are those of Juclge Huber in the Spanish Zone of Morocco claims that 'Responsibility is the necessary corollary of a right. All rights of an international character involve international responsibility."'

6. Todo Estado tem a obrigação de prevenir a ocorrência de danos com projeção internacional, bem como de abster-se do excrcício de seus próprios dircitos, quando os mesmos forem potencialmente uma fontc de danos que ultrapassem suas fronteiras, como a poluição atmosférica, mesmo $\mathrm{cm} s c$ tratando de atividades lícitas. Tais atividades tornam-sc ilicitas quando clas violam a obrigação internacional de nãointerferência.

7. QUIGLEY, John. Complicity in international law: a new direction in the law of state responsibility. The British Year Book of International Law 1986, Oxford: Clarendon Press, 1987, p. 78.

8. Projeto sobre Responsabilidade do Estado adotado pela Comissão de Dircito Internacional $\mathrm{cm} 11$ de agosto de 2000 (doravante, o "Projeto"), art. 43, "a"

9. Ibidem, art. 43, "b"

10. Uma organização internacional, por cxcmplo.

11. Projcto, art. 43, "b".

12. John Quiglcy, ob. cit., p. 78: "The International Law Commission has stated that a State is liable as an accessory whether the principal wrongful act is committed against a State or a particular group of States, a subject of international law other than a State, or the international community as a whole."

13. Idem, ibidem, p. 81: "Customary norms are developed by Sate practice." 
por ele ratificado, ele comete um ato ilícito internacional. ${ }^{14} \mathrm{O}$ Estado torna-se responsável por esta violação, cujas conseqüências podem ser graduadas em função da culpa ${ }^{15} \quad 16$

Não existe um tratado específico disciplinando, exaustivamente, a responsabilidade internacional dos Estados pela prática de atos ilícitos, ${ }^{17}$ este ramo do Direito Internacional Público ainda não foi completamente normatizado. Se levarmos em consideração a quantidade de comitês arbitrais, os EUA têm sido os participantes mais freqüentes em casos envolvendo a responsabilidade internacional do Estado. ${ }^{18} \mathrm{O}$ Direito Internacional tem sido apenas parcialmente efetivo em impedir que Estados violem direitos protegidos internacionalmente. ${ }^{19}$ A responsabilização dos Estados em função da prática de atos ilícitos ainda não atingiu um nível satisfatório de maturidade. ${ }^{20}$ Para que um Estado seja responsabilizado internacionalmente, devem-se esgotar os recursos internos. ${ }^{21}$

A Comissão de Direito Internacional tem procurado normatizar a responsabilidade dos Estados em virtude da prática de atos ${ }^{22}$ que são proibidos pelo Direito Internacional. ${ }^{23}$ O Projeto sobre Responsabilidade do Estado ${ }^{24}$, adotado pela

14. Pctcr Malanczuk, ob. cit., p. 254.

15. CAPOTORTI, Francesco. Cours génćral de droit international pubblic. In: Recueil des Cours 1994. Dordrecht/Boston/London, Acadćmic de Droit Intcrnational, (248):253, 1995: "/...J elle est considérée comme un facteur déterminant le degré des conséquences du fait illicite."

16. HIGGINS, R. Gencral Course on Public International Law. In: Recueil des Cours 199I, Dordrecht Boston/London: Académic de Droit International, (230):196-197, 1993.

17. John Quiglcy, ob. cit., p. 81: "There is as yet no treaty on the law of State responsibility."

18. WM. W. Bishop, ob. cit., pp. 385-386: "Measured by the international arbitral commissions set up to deal with groups of such claims, the United States has been the leading participant, appearing both as plaintiff and as defendant in these cases."

19. John Quiglcy, ob. cit., p. 104: "International law has proved only partially effective in keeping States form violating internationally protected rights."

20. Francesco Capotorti, ob. cit., p. 247 : "[...] il est au moins opportun d'attendre que le chapitre concernat les conséquences des faits illicites atteigne un niveau satisfaisant de maturité."

21. Idem, ibidem, p. 244 : "Dans ce cas, l'obligation peut être considérée violée dans le seul cas où les particuliers intéressés auraient épuisé les recours internes efficaces qui leurs sont disponibles, sans obtenir le traitement prévu par l'obligation (ou bien, dans les cas où cela n'était pas possible, un traitement équivalent)."

22. A Comissão de Dircito Internacional também tem procurado redigir um código internacional rclativo aos crimes contra a paz c segurança da Humanidade, bem como tem cstudado o tema da responsabilidade intemacional do Estado por danos causados por atividades lícitas, o que implicaria a obrigação de indenizar tercciros cm virtude de conseqüências danosas derivadas de atividades consideradas pcrigosas.

23. Francesco Caportorti, ob. cit., p. 272.

24. Entre paises com leis c costumes similares, com maior paridade $\mathrm{cm}$ termos de descnvolvimento cconômico, a responsabilização internacional do Estado pela prática de atos ilícitos pode ocorrer com mais raridade. A responsabilidade intcrnacional dos Estados pela prática de atos ilicitos constituiria um resquicio do colonialismo $\mathrm{c}$ do impcrialismo, aumentando o ressentimento das Nações pobres com relaçào às normas impostas pclas Naçõcs ricas. 
Comissão de Direito Internacional (CDI), em 11 agosto de $2000^{25}$ será analisado em seguida. Em princípio, a prática de qualquer ato ilícito internacional torna o Estado responsável internacionalmente. ${ }^{26}$

\section{Imputação pela prática de atos ilícitos.}

$\mathrm{O}$ ato ilícito internacional deve ser imputado, de acordo com o Direito Internacional, a um Estado. Todo Estado em cujo território ocorreu um ato contrário ao Direito Internacional tem a obrigação de dar explicações sobre o mesmo e de fornecer meios para a investigação do ocorrido. ${ }^{27}$

Para que um Estado seja responsabilizado, deve ter ocorrido uma conduta ilícita internacional que lhe possa ser imputada, pouco importando se esta conduta provém do Poder Legislativo, do Poder Executivo ou do Poder Judiciário, ${ }^{28}$ bem como se constitui uma ação ou uma omissão desses Poderes em agir em situações nas quais deveriam ter agido $^{29}$ e 30 . Quando o ato lesivo houver sido praticado pelo Poder Judiciário, em função de sua independência, o Estado só será responsabilizado, quando o tratamento judicial concedido ao estrangeiro houver sido ultrajante. ${ }^{31}$ Os Estados, que agem apenas mediante seus agentes, ${ }^{32}$ podem ser responsabilizados por condutas ilicitas internacionais praticadas por qualquer um de seus órgãos ${ }^{33}$ A conduta ilícita é imputada internacionalmente ao Estado não apenas porque o status do órgão é reconhecido pelo Direito Interno, mas porque a ação ou omissão específica foi executada por um agente investido na qualidade de órgão do Estado. ${ }^{34} \mathrm{Um}$ Estado pode ser mais facilmente responsabilizado quando o ato ilícito tiver sido praticado por agentes mais graduados. ${ }^{35}$

25. Ver: Lauterpacht Research Centre for International Law. Statc Responsibility Project. http:// www.law.cam.ac.uk/rcil/ILCSR/Statresp.htm (16.06.02)

26. Projcto, art. 1".

27. The Corfu Channel Case (United Kingdom of Great Britain and Northern Ircland / Pcople's Republic of Albania) I.C.J. Reports 1947-48.

28. Francesco Capotorti, ob. cit., p. 250: "L'appartenance de chaque institution au pouvoir constituant, à celui législatif," exécutif ou judiciaire. ou encore à un autre pouvoir; est une circonstance insignifiante, et il en va de même pour le caractère international ou interne des fonctions respectives, ainsi que pour leur position supérieure ou subordonnée dans le cadre de l'organisation de l'État (cela est établi par l'article 6)."

29. Projcto, art. $4^{\prime \prime}, \$ 1^{\circ}$.

30. WM. W. Bishop, ob. cit., p 393: "There must be internationally illegal conduct which can be attributed to the state, whether it be action by the legislative, executive and administrative, or judicial organs of that state, or failure of those organs to act in situations where they should have acted."

31. Idem, ibidem, p. 397.

32. Projeto, art. $4^{\prime \prime}, \S 2^{\prime \prime}$.

33. Projcto, art. $4^{\prime \prime}, \S 1^{\prime \prime}$.

34. Francesco Capotorti, ob. cit., p. 248.

35. WM. W. Bishop, ob. cit., p. 396 : "Liability may be more quickly found when the wrong is done by higher officials than by lower [...]." 
Todo Estado pode ser responsabilizado internacionalmente pela violação de obrigações internacionais, mesmo se tal violação for praticada por uma entidade que não constitua um órgão estatal, mas exerça elementos da autoridade estatal. ${ }^{36}$ Ele tem a obrigação de eliminar o incitamento à violência e de promover a disseminação de informações que não-incitem à violência, podendo ser responsabilizado internacionalmente em virtude da omissão em adotar medidas policiais ou judiciais para prevenir ou punir condutas ilícitas. Caso uma pessoa ou um grupo de pessóas praticar uma conduta ilícita a mando de um Estado, tal Estado também pode tornar-se responsável internacionalmente pela prática desta conduta. ${ }^{37}$

Qualquer Estado, no tratamento conferido aos estrangeiros, deve respeitar um padrão mínimo de Justiça, reconhecido internacionalmente. ${ }^{38}$ Não-basta que um Estado confira aos estrangeiros o mesmo tratamento concedido aos seus nacionais. Um padrão mínimo de Justiça, comum a todos os países civilizados, precisa ser respeitado no tratamento dos estrangeiros. ${ }^{39}$ A Declaração Universal de Direitos Humanos, de 1948, confirmou a existência de um padrão mínimo de Justiça, reconhecido internacionalmente. ${ }^{40}$

Várias espécies de conduta, provenientes tanto de funcionários públicos civis quanto de funcionários públicos militares, podem lesar estrangeiros. Sem considerar o não-cumprimento de tratados internacionais, pode-se mencionar a prisão ilegal, a lesão corporal, o assassinato de estrangeiros; a destruição da propriedade ou a apreensão arbitrária de bens pertencentes a estrangeiros; o não-cumprimento arbitrário de cláusulas contratuais celebradas com estrangeiros. Um Estado também pode ser responsabilizado internacionalmente por ter-se mostrado incapaz de proteger razoavelmente estrangeiros contra atitudes lesivas praticadas por indivíduos isoladamente, bem como por ter-se mostrado incapaz de processar ou punir tais indivíduos. ${ }^{41}$

Caso o ato lesivo ao estrangeiro houver sido praticado em virtude de distúrbios provocados por multidões, o Estado será responsabilizado caso se comprovar que seus agentes participaram destes distúrbios, ou que o Estado não se esforçou razoavelmente para impedir a ação das multidões, ou ainda que não se esforçou razoavelmente para processar e punir os participantes dos distúrbios. ${ }^{42}$ Um Estado que

36. Projcto, art. $5^{\circ}-9^{\prime \prime}$

37. Jbidem, art. 6".

38. JENNINGS, R.Y. General Course on Principles of International Law. In: Recueil des Cours 1967. Leyde: Académic de Droit International, (121):487, 1969: "Thus in the locus classicus of the international minimum standard - the Neer claim - the General Clains Conmission between the United States and Mexico defined the international standard in a much-quoted passage as follows: ... The propriety of governmental acts should be put to the test of international standards... .."

39. WM. W. Bishop, ob. cit., pp. 393-394.

40. R.Y. Jennings, ob. cit., p. 488.

4I. WM. W. Bishop, ob. cit., p. 396.

42. Ilem, ibiclem, p. 398. 
demonstre muito descaso em punir os responsáveis por um ato ilícito praticado contra um estrangeiro pode, efetivamente, terminar sendo considerado cúmplice na prática deste ato. ${ }^{43}$ Caso representantes de um Estado se envolverem na execução ilegal de um estrangeiro, tal Estado torna-se responsável por essa conduta ilícita.

Embora os agentes secretos franceses tenham supostamente agido ultra vires na explosão do "Rainbow Warrior", no porto de Auckland, Nova Zelândia, embarcação do Greenpeace que denunciava ao mundo os experimentos nucleares franceses no Atol de Mururoa, a França foi considerada responsável por tais atos. ${ }^{44} \mathrm{O}$ Estado pode tornar-se responsável por atos ultra vires de seus agentes, mesmo se tais atos tiverem sido praticados contrariamente a instruções dadas pelo próprio Estado. ${ }^{45}$

Danos sofridos por estrangeiros, praticados por revolucionários que não lograram transformar-se em autoridade constituída, não costumam ensejar a responsabilidade internacional do Estado. Parte-se do princípio de que revolucionários não são agentes do governo, e que o governo deve ter feito todo o possível para combater tal revolução. Quando, no entanto, os revolucionários conquistam o poder e se transformam em autoridade constituída, o Estado torna-se responsável pelos danos sofridos por estrangeiros durante a revoluçã $0^{46} \mathrm{e}^{47} \mathrm{O}$ Governo mexicano foi considerado como responsável pelo fuzilamento de cidadãos americanos durante a Revolução Mexicana. O Estado iraniano foi considerado responsável por não ter protegido os funcionários e os arquivos da Embaixada Americana dos ataques de militantes fundamentalistas no início da Revolução Islâmica. ${ }^{48}$

William Bishop, já em 1965, alertava para o não-cumprimento de cláusulas contratuais celebradas pelo Estado com estrangeiros. ${ }^{49}$ Qualquer espécie de contrato, inclusive licenças patentárias. Cláusulas contratuais desta natureza fundamentam-se no Direito Nacional, não no Direito Internacional. O Direito Internacional seria violado, caso o Estado lançasse mão de sua potestade para cancelar ou repudiar cláusulas contratuais. ${ }^{50}$

Não se atribuem ao Estado os atos ilícitos praticados por órgãos de outro Estado em seu próprio território, tampouco os de um órgão de uma organização internacional no território de um Estado, nem os de um movimento insurrecional, salvo

43. R.Y. Jennings, ob. cit., p. 496.

44. R. Higgins, ob. cit., p. 200.

45. Idem, ibidem, pp. 200-201.

46. Projcto, art. 10.

47. WM. W. Bishop, ob. cit., pp. 398-399.

48. Case Concerning United States Diplomatic and Consular Staff in Teheran: Order (Request for the Indication of Provisional Mcasures) 15.12.1979 (United States of Amcrica / Iran) I. C.J. Reports 1979.

49. WM. W. Bishop, ob. cit., p. 399.

50. Idem, ibidem, p. 399: "Violation of international law is more likely to be asserted, and found, when the state party to the contract has used its political power to cancel or repudiate the contract, in a way in which a private individual could not if the contract had been made with him instead of with the state." 
se o aparato estatal tiver sido colocado à disposição da prática do ato ilícito. ${ }^{51}$

Um Estado que auxilie outro Estado na prática de um ato ilícito internacional pode ser responsabilizado, caso aquele Estado estiver a par das circunstâncias que envolveram a prática do ato ilícito e se o ato se tornasse internacionalmente ilícito mesmo se tivesse sido praticado por ele ${ }^{52}$ es3 O Estado cúmplice também pode ser responsabilizado, já que sem seu auxílio o outro Estado não teria conseguido praticar o ato ilícito..$^{54}$

Várias são as hipóteses em que se fundamenta a cumplicidade: a) permitir que seu território seja utilizado para a prática de atos ilícitos; por exemplo: permitir a utilização de seu território como base logística para a prática de atos terroristas no Exterior; b) realizar atos políticos que promovam a prática de atos ilícitos; por exemplo: enviar missões diplomáticas que reconhecessem a jurisdição da Indonésia sobre TimorLeste; e c) ajudar materialmente outros Estados na prática de atos ilícitos; por exemplo: ajudar militarmente a Indonésia durante a ocupação de Timor-Leste. ${ }^{55}$

2. Elementos do ato ilícito.

É o Direito Internacional que caracteriza a ilicitude internacional de um ato praticado por um Estado, e não o Direito Nacional. ${ }^{56}$ Para que um Estado seja responsável por um ato ilícito internacional, é necessário que sua conduta, comissiva ou omissiva, Jhe seja imputável de acordo com o Direito Internacional. Tal conduta deve constituir uma violação de uma obrigação internacional ${ }^{57}$ e $5 k$ Quando um ato praticado por um Estado não se coaduna com o que é exigido dele por uma obrigação internacional, materializa-se o ato ilícito internacional. ${ }^{59}$ A existência do ato ilícito internacional independe da origem ou do caráter da obrigação violada, da fonte que a fez nascer. ${ }^{60}$ A obrigação pode ter uma origem consuetudinária ou convencional. $\mathrm{O}$ conteúdo da obrigação é indiferente no que diz respeito às consequiências da violação. O fator temporal, por outro lado, tem importância no exame da existência da violação de uma obrigação internacional. $O$ ato ilícito deve ocorrer no momento em que a obrigação violada estava em vigor com respeito ao Estado que a violou. ${ }^{\text {"1 }}$

51. Francesco Capotorti, ob. cit., p. 250.

52. Quem praticou o ilicito também é responsável, independentemente.

53. Projeto, art. 16.

54. Francesco Capotorti, ob. cit., p. 255.

55. John Quiglcy, ob. cit., pp. 83-95.

56. Projcto, art. $3^{\circ}$

57. Ibidem, art. $2^{\mathbf{0}}$.

58. Francesco Capotorti, ob. cit., p. 242.

59. Projcto, art. 12.

60. Ibidem, art. 12.

61. Ib., art. 13. 
A violação de uma obrigação internacional mediante um ato de um Estado que não tenha uma natureza contínua ocorre no momento em que o ato for praticado, mesmo se seus efeitos persistirem.62 A violação de uma obrigação internacional por um ato de um Estado que tenha uma natureza contínua, a seu turno, estende-se ao longo de todo o período durante o qual o ato continuar a ser praticado e não permanecer em conformidade com a obrigação internacional violada.63 A violação de uma obrigação internacional que exija de um Estado a não-ocorrência de um dado evento ocorre quando este sobrevier e estende-se durante todo o período em que o evento persistir e não permanecer em conformidade com a obrigação internacional violada. ${ }^{64}$

Por sua vez, a violação de uma obrigação internacional por um Estado mediante uma série de atos ou omissões definidas em seu todo como ilícitas verificase quando a ação ou omissão ocorrer de uma maneira que, levando em consideração outras ações ou omissões, seja suficiente para constituir o alo ilícito. ${ }^{65}$ Neste caso, a violação persiste enquanto tais ações ou omissões forem repetidas e não permanecerem em conformidade com a obrigação internacional. ${ }^{6 n}$

Não se pode procurar responsabilizar internacionalmente um Estado, caso não se respeitar o princípio da nacionalidade da reclamação e caso não se tiverem esgotado os recursos internos. ${ }^{67}$

\section{Nacionalidade.}

O estrangeiro não tem o direito de obrigar seu Estado de origem a tomar qualquer espécie de medida contra o Estado que teria lesado seus interesses. Cabe ao seu Estado de origem, discricionariamente, avaliar em que medida cumpre adotar medidas $^{68}{ }^{69} \mathrm{Se}$ a reclamação do seu nacional for considerada pertinente, o Estado de origem do estrangeiro procurará, mediante seus agentes diplomáticos, entrar em acordo com o Estado acusado de praticar o ilícito, que pode assumir incontinenti sua responsabilidade e pagar uma indenização, ou qualquer outra forma de reparação, ao estrangeiro que tiver sido lesado. Se esta tentativa não for bem sucedida, se os Estados não chegarem a um acordo, o litígio poderá ser submetido a arbitragem, ${ }^{70}$ ou mesmo à
62. $I b .$, art. $14,1^{\circ}$
63. $I b .$, art. $14, \S 2^{\circ}$
64. Ib., art. 14, § $3^{\circ}$
65. $I b$. , art. $15, \S 1^{\circ}$
66. $l b$. , art. $15, \$ 2^{\prime \prime}$
67. Ib., art. 45.

68. Case Conecrning the Barcelona Traction, Light and Power Company, Limited: Second Phase 05.02.1970 (Belgium / Spain) I.C.J. Reports 1970.

69. Peter Malanczuk, ob. cit., p. 257.

70. Quando dois Estados decidem recorrer à arbitragem, cle constitucm, por livre cscolha, um juizo arbitral, para julgar o litigio (Cf. ACCIOLY, Hildebrando. Manual de direito internacional público. São Paulo: Saraiva, II²d., 1985, p. 255). 
Corte Internacional de Justiça. ${ }^{71}$ Quando os Estados praticam sérias condutas antisociais contra estrangeiros, geralmente elas não podem ser satisfatoriamente combatidas sem que o Estado de origem do estrangeiro intervenha em seu socorro. ${ }^{72}$

Organizações internacionais, como as Nações Unidas, também podem demandar compensações em benefício de seus agentes. ${ }^{73}$ Se uma organização pode ser parte de tratados internacionais, ela também pode ser considerada responsável pelo descumprimento de cláusulas previstas num tratado internacional. ${ }^{74}$ Ao defender os interesses de seus agentes, uma organização internacional também estaria defendendo seus próprios interesses. ${ }^{75}$

Caso não haja um tratado específico que discipline o litígio, antes de o Estado de origem do estrangeiro agir, seja tentando, mediante seus agentes diplomáticos, convencer o Estado que teria lesado os interesses de seu nacional a pagar uma indenização, seja recorrendo a arbitragem, é preciso que se observem dois requisitos fundamentais. Primeiro, o estrangeiro precisa ser efetivamente nacional do Estado demandante. Segundo, os recursos locais, disponiveis no Estado demandado, devem ter sido esgotados. ${ }^{76}$

Para determinar se um estrangeiro é nacional do Estado demandante, deve-se observar o que dispõe a lei deste Estado. ${ }^{77}$ São poucos os precedentes em que comitês arbitrais não consideraram prejudicados casos dizendo respeito a indivíduos que eram nacionais tanto do Estado demandado quanto do Estado demandante. ${ }^{78}$

Quando se tratar de pessoas jurídicas, será o Estado de nacionalidade da pessoa jurídica que terá o direito de agir como Estado demandante, em benefício de seus interesses. A nacionalidade da empresa será, normalmente, determinada em função de sua sede social. Embora não se costume exigir que nacionais sejam proprietários da empresa que o Estado demandante pretende defender, se não houver uma substancial participação ${ }^{79}$ de nacionais do Estado na titularidade da pessoa jurídica, ${ }^{80}$ pode-se considerar que o Estado não tem interesse de agir. ${ }^{81}$

71. WM. W. Bishop, ob. cit., pp. 386-387.

72. R.Y. Jennings, ob. cit., p. 512.

73. Iclem, ibillem, p. 477.

74. Id., ib., p. 497 : "If an international oryanization can make treaties, it must also be capable of incurring liability for breach of a treaty."

75. Id., ib., p. 479.

76. WM. W. Bishop, ob. cit., p. 387.

77. Idem, ibidem, p. 388.

78. Id., ib., p. 390.

79. Como "substancial participação", pode-se entender o controle acionário de sociedades com capital aberto (Cf. BISHOP, WM. W. General Course of Public International Law. In: Recueil des Cours 1965. Lcydc: Acadćmic de Droit International, (115):389, 1965, p. 389).

80. Os nacionais que detćm o controle de uma empresa-matriz podem ter mais interesse de agir do que os nacionais de uma cmpresa-filial, já que aqueles sofrerào mais concretamente com os prejuizos que forem impostos àquela pelo Estado demandado (Cf. BISHOP, WM. W. General Course of Public International Law. In: Recueil des Cours 1965. Leydc: Académic de Droit International, (115):389-391, 1965).

81. WM. W. Bishop, ob. cit., p. 389. 
Caso não haja nenhum tratado dispondo em contrário, para que o Estado demandante tenha o direito de adotar medidas contra o Estado demandado, o indivíduo ou empresa precisa ser seu nacional não-só quando do surgimento do litígio, mas também quando do começo das negociações diplomáticas ou dos procedimentos judiciais. ${ }^{82}$ Deve haver a existência de um vínculo de nacionalidade quando do surgimento do dano. ${ }^{83}$

Como os indivíduos não seriam sujeitos do Direito Internacional, sua proteção só poderia ser alcançada mediante outras entidades jurídicas que gozam de personalidade jurídica internacional. ${ }^{84}$ Quando um Estado defende os interesses de seus nacionais, ele estaria defendendo seus próprios interesses. ${ }^{85}$ Ao defender um de seus nacionais, o Estado estaria defendendo a si mesmo. ${ }^{86} \mathrm{O}$ Estado constituiria o sujeito da demanda, enquanto o indivíduo, o objeto.$^{87} \mathrm{O}$ Estado sofre, indiretamente, um dano através de seu nacional. ${ }^{88}$ Não se pode procurar responsabilizar internacionalmente um Estado, caso o Estado lesado ${ }^{89}$ houver desistido da reclamação de uma maneira inequivoca ou caso se considerar que o mesmo, em função de sua conduta, aquiesceu validamente na prescrição da reclamação $0^{90}$ e 11

Com o estabelecimento de tribunais internacionais, aos quais os indivíduos possam recorrer para processar Estados estrangeiros por danos sofridos com desrespeito ao Direito Internacional, ${ }^{92}$ o processo de responsabilização do Estado por danos cometidos contra estrangeiros pode tornar-se menos sujeito a ingerências políticas. $^{93}$

82. Idem, ibidem, p. 391: "Thus for State A to establish its right to press the claim, the claim must have been of State A's nationality at the time it arose, and still be of State A's nationality at the time the claim is presented through diplomatic channels or taken before a tribunal."

83. R.Y. Jennings, ob. cit., p. 476: "[...] it should follow that the existence of a nationality link at the moment of the injury would suffice."

84. Idem, ibidem, p. 480.

85. Id., ib., p. 479.

86. Peter Malanczuk, ob. cit., p. 263.

87. R.Y. Jennings, ob. cit., p. 474: "The theory, then, is that the State is the subject of the claim, whilst the injured individual the mere object of the claim."

88. Idem, ibidem, p. 479.

89. Por "Estado Icsado", entende-sc, neste texto, o Estado sujcito às conseqüências da prática do ato ilícito.

90. Para a doutrina Calvo, cnunciada pelo jurista argentino Carlos Calvo, os estrangciros nào fariam jus a dircitos c privilćgios não concedidos aos nacionais. Portanto, $\mathrm{cm} \mathrm{sc}$ verificando tal hipótesc, os cstrangeiros não poderiam obrigar scu Estado de origem a tomar qualquer cspécic de medida contra o Estado que tcria lesado scus interesses.

91. Projcto, art. 46.

92. WM. W. Bishop, ob. cit., p. 414.

93. Idem, ibidem, p. 414. 
4. Esgotamento dos recursos internos.

Outro pré-requisito é o esgotamento dos recursos internos. O exercício da jurisdição doméstica associa-se a princípios com alta projeção política, como independência e soberania, ${ }^{94}$ que corporificam o respeito que cada Estado concede ao outro. Um indivíduo não pode, tendo sofrido as conseqüências de um ato ilícito internacional praticado por um Estado estrangeiro, processá-lo em seu país de origem. ${ }^{95}$ Para que um Estado demandante adote medidas contra o Estado demandado, os recursos internos precisam ser esgotados. Amistosamente, podem acordar, o Estado demandado e o Estado demandante, que o esgotamento dos recursos internos não constitui um prérequisito para a adoção de medidas. ${ }^{96} \mathrm{O}$ esgotamento dos recursos internos não é exigido, quando inexistirem recursos internos efetivos, ou quando o acesso aos mesmos revelarse irrelevante ${ }^{97}$ e 98

Um tribunal internacional não analisará uma demanda internacional em benefício de um nacional, caso não se comprovar que o nacional esgotou em vão os recursos internos disponiveis no Estado demandado. ${ }^{99}$ Ao Estado demandado, precisa ser dada a oportunidade de fazer Justiça em benefício do estrangeiro, em conformidade com seu próprio ordenamento jurídico. ${ }^{100}$ Uma companhia suíça, que teve seus bens apreendidos nos EUA durante a Segunda Guerra Mundial sob acusação de que tinha colaborado com a empresa alemã I.G. Farben, recorreu à Corte Internacional de Justiça (CIJ). A CIJ decidiu que os recursos internos não haviam sido exauridos ${ }^{101}$ Uma demanda internacional não constitui uma segunda instância, um recurso a uma decisão estrangeira considerada insatisfatória. Para que uma demanda internacional seja viável juridicamente, ela precisa se fundamentar em princípios do Direito Internacional. ${ }^{102}$ $\mathrm{O}$ dano sofrido pelo nacional do Estado demandante ${ }^{103}$ deve constituir um ilícito sob

94. R.Y. Jennings, ob. cit., p. 499.

95. CARON, David D. Iraq and the Force of Law: Why give a shicld of Immunity? American Journal of International Law, 85( (1):90, Jan. 1991.

96. WM. W. Bishop, ob. cit., p. 392.

97. O esgotamento dos recursos internos só é exigido quando o ato ilicito houver sido praticado nos limites da jurisdiçăo do Estado demandado. Se o ato ilicito houver sido praticado $\mathrm{cm}$ alto mar, ou no exterior, o esgotamento dos recursos intemos nào é exigida.

98. WM. W. Bishop, ob. cit., pp. 392-393.

99. R.Y. Jennings, ob. cit., p. 480.

100. Idem, ibidem, p. 480.

101. Intcrhandel Case (Switzerland / United States of America) I.C.J. Reports 1959.

102. Pcter Malanczuk, ob. cit., p. 268.

103. Caso o dano alegado for considerado como tendo sido sofrido diretamente pelo Estado demandante, ainda assim o csgotamento dos recursos internos pode ser cxigido (Cf. JENNINGS, R.Y. Gencral Coursc on Principles of International Law. In: Recueil des Cours 1967. Leyde : Académic de Droit Intcrnational, (121):482-483, 1969). 
o ponto de vista do Direito Internacional. ${ }^{104}$

O comportamento do Poder Judiciário pode ensejar a responsabilidade internacional do Estado, quando a autoridade judicial negar o acesso à Justiça ao estrangeiro, como meio deste fazer valer seus direitos subjetivos, ou houver atraso injustificado no exercício das funções judiciais. Também se incluiria nessa exceção a hipótese de pronunciamento de um julgamento com violação aberta à lei, do qual um estrangeiro seja vítima. ${ }^{105}$

\section{Circunstâncias excluindo a ilicitude.}

Várias circunstâncias podem excluir a ilicitude de um ato internacional, interrompendo o nexo causal entre a prática do ato ilícito e a responsabilidade do Estado que é autor deste ato. As circunstâncias são as seguintes: consentimento, ${ }^{106}$ cumprimento de uma norma imperativa de Direito Internacional, ${ }^{107}$ legítima defesa, ${ }^{108}$ represálias com respeito a um ato ilícito internacional, ${ }^{109}$ força maior, ${ }^{110}$ extrema necessidade ${ }^{\prime \prime \prime}$ e estado de necessidade ${ }^{\prime \prime 2}$.

O consentimento exclui a ilicitude de um ato internacional se o ato praticado circunscrever-se dentro dos limites deste consentimento. ${ }^{113} \mathrm{O}$ consentimento deve ser anterior ou contemporâneo à prática do ato ilícito, já que um consentimento posterior equivaleria à renúncia ao direito do Estado lesado de obter reparação. ${ }^{1 / 4} \mathrm{~A}$ exclusão da ilicitude não ocorrerá se a obrigação derivar de uma norma imperativa de Direito Internacional geral. Um ato internacional perde sua natureza ilícita se se tornar obrigatório em virtude de uma norma imperativa de Direito Internacional; é muito dificil que isto ocorra. ${ }^{115} \mathrm{~A}$ definição de norma imperativa de Direito Internacional geral está prevista na Convenção de Viena sobre Direito dos Tratados, art. 53. ${ }^{116}$

104. R.Y. Jennings, ob. cit., p. 481: "Indeed the claim is bound to be different from the claim before the municipal courts if only because it is now the claim of the State and no longer the claim of the individual."

105. Francesco Capotorti, ob. cit., p. 251.

106. Projcto, art. 20:

107. Ibidem, art. 21.

108. $J b$., art. 22.

109. Ib., art. 23.

110. Ib., art. 24.

111. Ib., art. 25.

112. Ib., art. 26.

113. Ib., art. 20.

114. Francesco Capotorti, ob. cit., p. 256 : “[ ...J un consentement postérieur serait au contraire une renonciation au droit de l'État lésé d'obtenir la réparation."

115. Idem, ibidem, p. 243.

116. Convenção de Viena sobre Dircito dos Tratados, art. 53: "É nulo o tratado que, no momento de sua conclusão, conflita com uma norma imperativa de direito internacional geral. Para os fins da presente 
Outra circunstância que exclui a ilicitude de um ato internacional - e não enseja, portanto, a responsabilidade do Estado que agiu - verifica-se quando o ato representa uma medida legítima de autodefesa, tomada em conformidade com a Carta das Nações Unidas. ${ }^{117}$ Considera-se admissivel a legítima defesa com respeito a um Estado que tenha enviado grupos armados ao território de outro Estado. ${ }^{118} \mathrm{~A}$ Carta das Nações Unidas, art. 51, reconhece o direito natural à legítima defesa contra uma agressão armada. Ela estabelece duas espécies de limites à legítima defesa. Um Estado-membro das Nações Unidas só pode lançar mão da legítima defesa, caso for objeto de uma agressão armada (limite objetivo) e até que o Conselho de Segurança tenha tomado as medidas necessárias para manter a paz e a segurança internacionais (limite temporal).

Um Estado pode lançar mão de represálias contra um Estado responsável pela prática de um ato ilícito internacional. ${ }^{119}$ As represálias armadas são proibidas, bem como a utilização da força ou a ameaça de sua utilização ${ }^{120}$ e 121 Tampouco as represálias podem violar direitos humanos fundamentais, obrigações de caráter humanitário, obrigações derivadas de normas imperativas de Direito Internacional geral e a obrigação de respeitar a inviolabilidade de agentes diplomáticos ou consulares. ${ }^{22}$ As represálias devem ser limitadas à suspensão do cumprimento de uma ou mais obrigações internacionais. ${ }^{123}$

Toda represália deve ser proporcional em relação ao prejuizo sofrido, levando-se em consideração a gravidade do ato ilícito internacional e os direitos em questão $^{124}$ e 125 . A adoção de represálias ${ }^{126}$ não deve colocar em risco a paz e a segurança internacionais. ${ }^{127}$ Não se admite a adoção de represálias, caso se tenha submetido a disputa a um tribunal judicial ou arbitral com o poder de tomar decisões obrigatórias

Convenção, uma norma imperativa de direito internacional geral é uma norma aceita e reconhecida pela comunidade internacional dos Estados no seu conjunto, como norma da qual nenhuma derrogação é permitida e que só pode ser modificada por nova norma de direito internacional getal da mesma natureza."117. Projcto, art. 22.

118. Case Concerning Military and Paramilitary Activities in and against Nicaragua (Nicaragua / United States of America) I.C.J. Reports 1984.

119. Projeto, art. 50, $\$ 1^{\circ}$.

120. Projcto, art. $51, \S 1^{\circ}$, “a”.

121. Francesco Capotorti, ob. cit., p. 257.

122. Projcto, art. 51, § l", “b”, “c" “d"c "c".

123. Ibidem, art. $50, \S 2^{\circ}$.

124. Ib., art. 52.

125. Francesco Capotorti, ob. cit., p. 258.

126. A Organizaçào Mundial do Comércio (OMC) entendeu que a Scção 301 da Lci Comcrcial Amcricana não diverge dos principios cstabclecidos pclo GATT (Cf. MURPHY, Scan. D. WTO Upholds U.S. Section 301 Trade Authority as GATT-Consistent. American Journal of International Law. 94(2):376377, April 2000).

127. Francesco Capotorti, ob. cit., p. 270. 
entre as partes, ${ }^{128}$ tampouco caso o ato ilícito internacional houver cessado, ${ }^{129}$ ou enquanto as negociações entre os Estados forem levadas a cabo com boa-fé e desde que as mesmas não hajam sido postergadas indevidamente ${ }^{130}$ e 131 . As represálias têm de ser interrompidas tão logo o Estado responsável responda pelos danos decorrentes da prática do ato ilícito internacional. ${ }^{132}$

A força maior também constitui uma causa de exclusão da ilicitude de um ato ilícito internacional, ${ }^{133}$ bem como a extrema necessidade ${ }^{134}$ e o estado de necessidade, ${ }^{135}$ conforme mencionado anteriormente.

Define-se força maior como uma força irresistivel ou um evento exterior imprevisto, fora do controle do Estado interessado, que lhe tornaram materialmente impossível agir de conformidade à sua obrigação. ${ }^{136}$ A força maior, um acontecimento exterior imprevisto, fora do controle, implica a impossibilidade absoluta de cumprir uma obrigação. ${ }^{137} \mathrm{O}$ Estado não responde, em caso de força maior. Não se exclui a ilicitude de um ato do Estado por força maior, caso o Estado em questão houver contribuido, seja isoladamente ou em combinação com outros fatores, para a ocorrência da força maior, ou se o Estado houver assumido o risco de ocorrência da força maior. ${ }^{138}$

Uma situação de extrema necessidade verifica-se quando o autor do ato ilicito não dispunha de outro meio razoável para salvar sua existência ou a de pessoas confiadas aos seus cuidados. ${ }^{139}$ Esta exclusão de ilicitude não incide caso a situação de extrema necessidade resultar, seja sozinha ou em combinação com outros fatores, da conduta do Estado que a invocar, ou se o ato ilícito em questão ensejar provavelmente um perigo comparável ou maior. ${ }^{140}$

O estado de necessidade não pode ser invocado por um Estado, como justificativa para a prática de um ato ilícito, se não ocorrerem duas condições. Primeiro, o ato ilícito deve constituir o único meio para salvaguardar um interesse essencial contra um perigo grave e iminente. Segundo, o ato ilícito não deve colocar seriamente em risco um interesse essencial do Estado ou dos Estados com relação aos quais a

128. Projeto, art. 53, § 5", "b".

129. Ibidem, art. $53, \S 5^{\circ}$, "a".

130. $l b$., art. $53, \S 4^{\circ}$.

131. Francesco Capotorti, ob. cit., p. 270.

132. Projeto, art. 55.

133. Ibidem, art. 24.

134. Ib., art. 25.

135. Ib., art. 26.

136. Ib., art. $24, \S 1^{\prime \prime}$

137. Francesco Capotorti, ob. cit., p. 259.

138. Projcto, art. 24, $\S 2^{\circ}$.

139. Ibidem, art. $25, \S 1^{\circ}$.

140. $1 b$., art. $25, \S 2^{\circ}$. 
obrigação internacional tem validade, ou da comunidade internacional como um todo. ${ }^{141}$ Tampouco se pode invocar o estado de necessidade como causa de exclusão da ilicitude de um ato internacional, se a obrigação decorrer de uma norma imperativa de Direito Internacional geral, ou se a própria obrigação for prevista por um tratado que exclua, de forma explícita ou implícita, a possibilidade de invocar-se o estado de necessidade, ou enfim se o Estado em questão houver contribuído para o surgimento do estado de necessidade. ${ }^{142}$

Todas as circunstâncias que excluem a ilicitude de um ato internacional não prejudicam a indenização por qualquer dano causado pelo ato em questão. Tampouco se podem continuar a argüir quaisquer das circunstâncias que excluem a ilicitude de um ato internacional com o objetivo de não se cumprir a obrigação em questão, caso a circunstância que excluía a ilicitude não mais existir. ${ }^{143}$

\section{Conseqüências jurídicas do ato ilícito.}

A cessação ${ }^{144}$ e a não-repetição do ato ilícito constituem meios tardios de respeitar a obrigação violada; elas independem de qualquer solicitação do Estado lesado. ${ }^{145} \mathrm{O}$ Estado responsável pela prática do ato ilícito tem o dever de continuar a respeitar a obrigação violada. ${ }^{146}$

O Estado responsável pela prática de um ato ilícito internacional tem a obrigação $^{147}$ de indenizar integralmente o dano provocado pelo ato ilícito, tenha ele uma natureza material ou moral. ${ }^{148} \mathrm{~A}$ indenização pode ser reduzida quando o prejuízo for em parte atribuido a outras causas, como, por exemplo, à conduta comissiva ou omissiva do Estado lesado. ${ }^{149} \mathrm{O}$ Estado responsável não pode justificar a prática de um ato ilícito com fundamento em dispositivos de seu Direito Interno. ${ }^{150}$ Uma obrigação internacional pode ser devida a outro Estado, a vários Estados ou à comunidade internacional como um todo. ${ }^{151}$ Os tribunais internacionais ainda não desenvolveram uma teoria coerente para a avaliação dos danos provocados por atos ilícitos

141. Ib., art. $26, \S 1^{\circ}$

142. Ib., art. $26, \S 2^{\circ}$

143. Ib., art. 27.

144. Excmplos de modalidades de cessação do ato ilicito: abandono do território ocupado, libertação de pessoas aprisionadas.

145. Projcto, art. 30.

146. Projcto, art. 29.

147. A violação de uma obrigação internacional acarreta a obrigação de reparar os danos de uma forma adcquada.

148. Projcto, art. $31, \S 2^{\circ}$

149. Ibidem, art. 40 .

150. lb., art. 32.

151. Ib., art. 34 . 
internacionais. ${ }^{152} \mathrm{~A}$ indenização geralmente é calculada em função do prejuízo sofrido pelos indivíduos, não pelo Estado demandante. ${ }^{153}$ Algumas atividades lícitas, de acordo com convenções internacionais, tendo provocado danos, podem ensejar a responsabilidade internacional do Estado. ${ }^{154}$

Três são as modalidades de indenização pelos danos causados por atos ilícitos internacionais: restituição ${ }^{155}$, compensação ${ }^{156}$ e satisfação ${ }^{157} \mathrm{O}$ Estado responsável por um ato ilícito não é obrigado a submeter-se a uma exigência unilateral de indenização por parte do Estado lesado; ${ }^{158}$ nem sempre as consequiências de um ato ilícito internacional são reparadas. ${ }^{159} \mathrm{~A}$ obrigação de indenizar o prejuízo sofrido pelo Estado lesado depende de sua conexão com o ato ilícito, através de um liame ininterrupto de causalidade. ${ }^{160}$

$\mathrm{A}$ indenização ${ }^{161}$ dos prejuizos provocados por ato ilícito internacional pode envolver tanto a restituição ao status quo ante ${ }^{162}$ quanto compensação pecuniária, ou ambos. ${ }^{163}$ Todo Estado responsável pela prática de um ato ilícito internacional tem o dever de efetuar a restituição, ou seja, de restabelecer a situação que existia antes da prática do ato ilícito, desde que tal restituição não seja materialmente impossível e não compreenda um ônus desproporcional ${ }^{164}$ e 165 . A restituição in natura difere da cessação do ato ilícito. Ela deve ser acompanhada do restabelecimento da situação existente

152. David D. Caron, ob. cit., p. 34.

153. Peter Malanczuk, ob. cit., p. 257.

154. Francesco Capotorti, ob. cit., p. 254 : "Il faut souligner enfin que, sur la base cle certaines conventions internationales, le fait que quelques activités étatiques, bien que parfaitement licites, aient provoqué des dommages est considéré comme un fondement de la responsabilité de l'État agent."

155. Projcto, art. 36.

156. Ibiclem, art. 37.

157. Ib., art. 38.

158. Christine Gray, ob. cit., p. 30.

159. Idem, ibidem, p. 29.

160. Francesco Capotorti, ob. cit., p. 265 : "Dans la pratique internationale, la possibilité d' indenniser le dommge subi par l'État lésé dépend de sa connexion avec le fait illicite, à travers un lien ininterrompu de casualité."

161. A taxa de juros, que deve assegurar a indenizaçāo integral dos prejuizos provocados pela prática de um ato ilicito internacional, é calculada a partir da data $\mathrm{cm}$ que a quantia principal deveria ter sido paga atć a data cm que a obrigação de pagar for cumprida (Cf. Projcto, art. 39).

162. A restituiçăo ao status quo ante podo ocorrer, por cxcmplo, quando o Estado cessa a conccssão de ajuda material a outro Estado envolvido na prática de atos ilicitos internacionais.

163. John Quiglcy, ob. cit., p. 125.

164. A restituição não deve ser excessivamente oncrosa para o Estado autor do ato ilieito internacional, pondo gravemente cm perigo scu sistema político, cconômico ou social. (Cf. CAPOTORTI, Francesco. Cours général de droit international pubblic. In: Recueil des Cours 1994. Dordrecht/Boston/London: Acadćmic de Droit International, (248):263, 1995).

165. Projeto, art. 35. 
antes da prática desse ato ${ }^{166}$ e 167 . A restituição geralmente é fruto de um acordo. ${ }^{168} \mathrm{Em}$ não sendo possível a restituição integral, ao status quo ante, recorre-se à compensação ${ }^{169}$ - 170 O Estado lesado tem o direito de exigir uma reparação pecuniária para que se substitua, em parte ou completamente, a restituição integral, inclusive quando o prejuizo não estiver inteiramente coberto pela restituição in natura. A compensação tem de eliminar todas as conseqüências do ato ilícito, de maneira que se restabeleça a situação que haveria existido, caso o ato ilícito não houvesse sido praticado. ${ }^{171}$ Tanto os danos emergentes quanto os lucros cessantes devem ser indenizados ${ }^{172} 173$ Exigiu-se compensação pecuniária dos vencidos na Primeira Guerra Mundial. ${ }^{174}$

Uma alternativa à restituição e compensação, a satisfação efetua uma reparação ao dano moral, e não-material, sofrido pelo Estado lesado. ${ }^{175}$ Ela tende a reparar o prejuízo jurídico, que consiste na violação de uma obrigação internacional primária, através da confirmação do valor obrigatório da obrigação desrespeitada. ${ }^{176}$ Constituem modalidades de satisfação, que não deve ser desproporcional ao prejuízo sofrido nem assumir uma forma humilhante para o Estado responsável pela prática do ato ilícito, ${ }^{177}$ por exemplo, a apresentação de desculpas, o pagamento de uma quantia simbólica de dinheiro. ${ }^{178}$

Quando vários Estados forem lesados em função da prática de um mesmo ato ilicito internacional, cada Estado lesado pode, separadamente, invocar a

166. O Irã foi obrigado a colocar um fỉm à detenção ilicita do corpo diplomático amcricano, garantir os meios de transportc para a saida do território iraniano, restituir os bens c documentos que pertenciam à cmbaixada c aos consulados dos EUA no Irã (Casc Concerning United States Diplomatic and Consular Staff in Tcheran: Order (Request for the Indication of Provisional Measures) 15.12.1979 (Unitcd States of Amcrica / Iran) I. C.J. Reports 1979).

167. Francesco Capotorti, ob. cit., p. 263.

168. Christine Gray, ob. cit., p. 35: "Their rarity, and the fact that their award is generally made on the basis of a compromis that makes express provision for this, cotmt against the primacy of restitutio in integrum in international law."

169. Projeto, art. $37, \$ 10$

170. John Quiglcy, ob. cit., p. 125.

171. Christine Gray, ob. cit., p. 27: "The essential principle contained in the actual notion of an illegal act - a principle which seems to be established by international practice an in particular by the decisions of arbitral tribunals - is that reparation must, as far as possible, wipe out all the consequences of the illegal act and re-establish the situation which would, in all probability, have existed if that act had not been committed."

172. Projeto, art. $37, \S 2^{\circ}$.

173. Francesco Capotorti, ob. cit., p. 265 : "On doit donc indemniser le préjudice matériel éprouvé (c'est-à-dire la perte patrimoniale que l'État lésé a subi) ainsi que le manque à gagner (c'est-à-dire la perte des profits, que le fait illicite a empêché d'atteindre)."

174. John Quiglcy, ob.cit., p. 127.

175. Projcto, art. $38, \S 1^{\circ}$.

176. Francesco Capotorti, ob. cit., p. 266.

177. Projeto, art. $38, \$ 3^{\circ}$.

178. Ibidlem, art. $38, \S 2^{\circ}$ 
responsabilidade do Estado que cometeu o ato ilícito. ${ }^{179} \mathrm{Se}$ vários Estados forem responsáveis pelo mesmo ato ilícito internacional, a responsabilidade de cada Estado pode ser invocada com relação a tal ato. ${ }^{180}$ Qualquer outro Estado, além do Estado lesado, pode invocar a responsabilidade internacional de outro Estado, desde que a obrigação violada seja devida a um grupo de Estados, incluindo aquele Estado lesado, e tenha sido celebrada para assegurar a proteção de um interesse coletivo; ou desde que a obrigação violada seja devida à comunidade internacional como um todo. ${ }^{181}$

A Comissão de Compensação das Nações Unidas constituiu um mecanismo para coletar, avaliar e propiciar compensação para dezenas de milhares ou milhões de reclamações contra os danos resultantes diretamente da invasão e ocupação do Kuwait pelo Iraque. ${ }^{182}$ A Comissão de Compensação das Nações Unidas, que começou a funcionar em Genebra, em julho de 1991, foi uma resposta direta à invasão do Kuwait, em agosto de 1990. Em setembro de 1992, 150 mil reclamações haviam sido protocolizadas. ${ }^{183}$ A causa jurídica da responsabilidade do Iraque pelos prejuizos causados foi a invasão ilegal e ocupação do Kuwait, de acordo com a Resolução n. $687 .{ }^{184}$ Mesmo apátridas puderam apresentar reclamações. ${ }^{185}$ A maior ênfase foi sobre reclamações individuais, ${ }^{186}$ que envolviam sobretudo danos pessoais, inclusive de natureza psicológica. Esta categoria compreende crimes sexuais, tortura, lesões corporais, seqüestro, cárcere privado, morte de parentes ou cônjuge. Danos materiais, com destruição de propriedade, bem como descumprimento de contratos e transações comerciais frustradas, também foram objeto das reclamações apresentadas. ${ }^{187}$

Uma violação séria ${ }^{188}$ de uma obrigação essencial para a proteção dos interesses fundamentais da comunidade internacional tem conseqüências específicas. ${ }^{189}$ A indenização a ser exigida, neste caso, deve refletir a gravidade da violação. ${ }^{190} \mathrm{Os}$ demais Estados da comunidade internacional não devem reconhecer como lícita a situação criada em função desta espécie de violação. Tampouco tais Estados devem

179. Ib., art. 47.

180. Ib., art. $48 \S 1^{\circ}$.

181. Ib., art. 49.

182. CROOK, John R. The United Nations Compensation Commission - A New Structure to Enforce Statc Responsibility. American Journal of International Law. 87(1):144, Jan. 1993.

183. Idem, ibidem, p. 144.

184. Id., ib., p. 147.

185. Id., ib., p. 149: "[...] even stateless persons may have their claims brought before the Commission." 186. Id., ib., p. 150: "The Commission's greatest emphasis to date has been on the claim of individuals." 187. Id., ib., pp. 153-156.

188. Uma violação ć considerada sćria se comprecnder uma falha grande ou sistemática por parte do Estado responsável no que diz respcito ao cumprimento da obrigação, podendo provocar um dano substancial aos interesses fundamentais protegidos pela mesma (Cf. Projeto, art. $41, \S 2^{\circ}$ ).

189. Projcto, art. 42.

190. Projeto, art. $42, \S 1^{\circ}$. 
prestar qualquer espécie de ajuda que auxilie a manutenção desta situação ao Estado responsável por este gênero de ato ilícito internacional. Eles devem cooperar para que a violação seja extinta. ${ }^{191}$

Conclusão.

O Projeto sobre Responsabilidade do Estado, adotado pela Comissão de Direito Internacional (CDI), em 11 agosto de 2000, que foi analisado no decorrer deste trabalho, constitui em boa parte um projeto em aberto, que não unifica completamente o assunto abordado. Seus artigos não se aplicam quando as conseqüências jurídicas de um ato ilicito internacional forem determinadas por normas especiais (lex specialis) de Direito Internacional. ${ }^{192}$ Tampouco eles regem necessariamente qualquer questão que possa surgir em relação à responsabilidade de uma organização internacional pela prática de atos ilícitos, bem como qualquer questão relacionada à responsabilidade individual de quem se incumba das funções de agente estatal. ${ }^{193}$

Os Estados costumam negociar suas diferenças, lançando mão de meios políticos $^{194}$ de solução de controvérsias, em vez de recorrer a meios jurídicos ${ }^{195}$ e 196 Talvez tal preferência por mecanismos com cunho político de solução de controvérsias seja responsável pela responsabilização inadequada, ou virtual não-responsabilização, de vários Estados pela prática de atos ilícitos, como com o genocídio ocorrido em Timor-Leste. ${ }^{197}$

Tem-se aventado a possibilidade de adotar um código internacional relativo aos crimes contra a paz e a segurança da Humanidade. O projeto de código disciplina os crimes cometidos por indivíduos. Esta é uma diferença essencial com relação à responsabilidade internacional dos Estados pela prática de atos ilícitos. $\mathrm{O}$ código seria dividido em duas partes: a primeira teria dois capítulos (definição e princípios gerais), e a segunda, apenas um (crimes contra a paz e a segurança da Humanidade). O projeto foi aprovado pela Comissão de Direito Internacional (CDI)

191. Projcto, art. $42, \S 2^{\circ}$.

192. Projcto, art. 56.

193. Projeto, arts. 57 c 58.

194. As negociaçõcs dirctas, os congressos c conferências, os bons oficios, a mcdiação, o sistcma consultivo (Cf. ACCIOLY, Hildcbrando. Manual de direito internacional público. São Paulo: Saraiva, $11^{\mathrm{A}} \mathrm{cd} ., 1985$, pp. 243 c 255 ).

195. A arbitragem, a solução judiciária, as comissões de inquérito c conciliação, as comissões mistas (Cf. ACCIOLY, Hildcbrando. Manual de direito internacional público. São Paulo: Saraiva, $11^{-4} \mathrm{~cd} ., 1985$, pp. 243 c 255).

196. ANDERSON, David. Negotiation and Dispute Settlement. In: Remedies in International Law: The Institutional Dilemma. Ed. por Malcolm D. Evans. Oxford: Hart Publishing, 1998, p. 112.

197. DUNN, James. East Timor: A Casc of Cultural Genocide? In: Genocide: Conceptual and Historical Dimensions. Ed. por George J. Andrcopoulos. Philadelphia: University of Pennsylvania Press, pp. $171-190$. 
em 12 de julho de 1991. Foi submetido à análise dos Governos dos Estados-membros das Nações Unidas, estando, portanto, sujeito a modificações. ${ }^{198}$

Brasília, maio de 2002.

198. Francesco Capotorti, ob. cit., p. 24I. 